\title{
Filosofia da educação: contribuições da teoria crítica para pesquisa educacional
}

\author{
Mauricio Rebelo Martins*
}

\section{Resumo}

O presente artigo tem o objetivo de apresentar algumas contribuições da teoria crítica para a pesquisa educacional. Nesse sentido, em primeiro lugar, argumenta-se a favor da associação a essa tradição que se orienta pelo ideal de emancipação. Em segundo lugar, recuperando as origens dessa tradição, busca-se aproximar as pesquisas normativas das pesquisas empíricas e, de modo especial, das manifestações culturais e estéticas. Defende-se que uma aproximação entre essas pesquisas contribui para identificarmos os principais desafios da educação e suas instituições no contexto complexo e plural das nossas sociedades. Por fim, destaca-se a importância de as pesquisas educacionais assumirem uma postura descritiva e normativa. É também necessário identificar os potenciais emancipatórios não impulsionados nas instituições educativas.

Palavras-chave: Educação. Filosofia. Pesquisa. Teoria crítica.

\section{Introdução}

A aproximação entre filosofia e educação pode ser encontrada já nos textos de Platão. Desde lá, encontramos filósofos que tematizaram a educação direta ou indiretamente. De outro modo, existiram também filósofos que não trataram da educação, mas que disponibilizaram em suas obras elementos e conceitos que contribuem para a pesquisa educacional. De toda forma, a educação nunca foi um tema estranho aos filósofos. Pelo contrário, para alguns, como Jean-Jacques Rousseau (2004), a educação foi um dos temas centrais.

Contrariando essa tradição, a filosofia da educação foi negligenciada no Brasil por muitos anos. Talvez porque existe quem defenda que a educação não pode ser tratada pela filosofia. Apesar disso, um grupo de professores está trabalhando há

\author{
Recebido: 23/02/2016 - Aprovado: 14/07/2016 \\ http://dx.doi.org/10.5335/rep.v23i2.6541
}

Doutorando em Filosofia e História da Educação na Universidade Estadual de Campinas. Licenciado em Filosofia e mestre em Educação pela Universidade de Passo Fundo. E-mail: maurebelo@gmail.com 
anos para mostrar que a filosofia da educação é, sim, um campo de investigação. Esse grupo de professores-pesquisadores trabalha, simultaneamente, com os objetivos de caracterizar esse campo de investigação e pensar os principais desafios da educação na atualidade.

Posso dizer que existem tantas filosofias da educação quanto existem filosofias. Quer dizer, no decorrer da história do pensamento filosófico, encontramos formas distintas de fazer filosofia. Nesse sentido, analisar a educação e suas instituições filosoficamente implica assumir um determinado referencial teórico e epistemológico. Antes de qualquer coisa, aquele que se dedica a pensar filosoficamente a educação deve ter clareza com quais referenciais está operando.

No meu caso, minhas pesquisas sobre a educação são orientadas por uma tradição conhecida como teoria crítica. Para esclarecer melhor minha posição sobre a filosofia da educação, em um primeiro momento, irei apresentar brevemente a tradição da teoria crítica (1). Em seguida, busco mostrar como essa tradição pode contribuir para pesquisa educacional (2). Por fim, pretendo tratar sobre a filosofia da educação como um exercício de aproximação com as pesquisas empíricas e com as manifestações culturais e estéticas (3).

O desenvolvimento de uma teoria da educação, formulada em uma relação sistemática com a filosofia da educação e uma teoria da sociedade, pode enfrentar a empreitada de pensar a educação de uma perspectiva que privilegie a orientação ética e política da ação educativa. Isto é, ao pensar a educação não podemos ignorar suas responsabilidades relacionadas à formação da cidadania e à sobrevivência e consolidação da democracia. Quem realiza uma pesquisa desde uma concepção crítico-normativa escolhe olhar para a realidade e tentar compreendê-la e explicá-la desde o juízo do que ela deveria ser.

Por isso, entendo que é fundamental resgatar a teoria da educação como um saber normativo. Emile Durkheim (2010) afirmava que para pensar a educação não podemos nos limitar às pesquisas empíricas. É claro que o sociólogo Durkheim valorizava esse tipo de pesquisa. Mas ele também nos alertava para o dever de a teoria da educação orientar a prática educativa, que é histórica e dinâmica, marcada pelo crescimento das novas gerações e pela própria transformação da sociedade. Por essa razão, pensar a educação no horizonte do dever ser constitui-se uma tarefa tão importante quanto dedicar tempo às pesquisas empíricas.

Não se trata de afirmar que a pesquisa empírica não tem valor algum. $\mathrm{O}$ problema central é que o acentuado desenvolvimento das pesquisas empíricas em educação praticamente extinguiu as pesquisas de caráter normativo. Pensar a rea- 
lidade educacional na tentativa de ver nela mesma os potenciais emancipatórios que podem ser impulsionados é uma finalidade que não pode ser desprezada. Pelo contrário, estimular o desenvolvimento de pesquisas normativas pode proporcionar o tempo necessário às pesquisas empíricas para elas avaliarem suas hipóteses.

Nesse sentido, minha pesquisa insere-se na tradição da teoria crítica e também está associada ao movimento daqueles que escolhem defender a educação pública e o seu compromisso com a sobrevivência e a consolidação da democracia. Fazer filosofia da educação significa investigar quais são os obstáculos à emancipação e as potencialidades emancipatórias que podem ser impulsionadas. Trata-se de olhar para a realidade educacional e tentar identificar o que está inibindo as novas gerações de marcharem na direção da autonomia.

A tradição da teoria crítica refere-se ao pensamento de um grupo de intelectuais marxistas não ortodoxos, alemães, alguns deles filhos de judeus, que, a partir dos anos 1920, desenvolveram pesquisas e intervenções teóricas sobre problemas filosóficos, econômicos, sociais, culturais e estéticos gerados pelo capitalismo de sua época. Essa tradição também ficou conhecida como Escola de Frankfurt, pois esse grupo fundou na cidade de Frankfurt, na Alemanha, o Instituto de Pesquisa Social, em funcionamento até os dias atuais.

Dentre os pensadores mais conhecidos dessa tradição estão: Max Horkheimer (1895-1973), diretor do instituto de 1930 até 1967, Herbert Marcuse (1898-1979), Theodor Adorno (1903-1969), que dirigiu o instituto de 1967 a 1969, Walter Benjamin (1892-1940) e Jürgen Habermas (1929), filósofo e sociólogo, ainda vivo. Desde 2001, o diretor do Instituto de Pesquisa Social é Axel Honneth (1949), filósofo e sociólogo alemão. Expoente da chamada terceira geração da teoria crítica, Axel Honneth (2003) ganhou renome internacional com sua teoria do reconhecimento.

A teoria crítica é uma tradição que se caracteriza, de modo amplo, por pelo menos dois aspectos importantes. Primeiro, o teórico crítico olha para a sociedade e procura ver o que nela está bloqueando a emancipação dos sujeitos. Mas não apenas isso, também é tarefa do teórico crítico olhar essa realidade e explorar as possibilidades de emancipação que nela estão presentes. Ou seja, é característico da teoria crítica orientar-se pela ideia ou pelo ideal de emancipação.

Para essa tradição, é impossível mostrar como as coisas realmente são senão a partir da perspectiva de como elas deveriam ser. É preciso olhar para a sociedade e procurar entender porque suas potencialidades emancipatórias não são concretizadas. Isso significa que existem tendências estruturais que tendem a perpetuar os entraves que nos impedem de alcançar a emancipação. Mas como a teoria crítica é uma teoria normativa, ela também investiga as tendências potenciais da ação que nos permitem superar esses entraves. 
O segundo aspecto está relacionado ao fato de a teoria crítica representar uma continuidade do trabalho de Marx (1818-1883). Dessa forma, a exemplo de Marx, os teóricos críticos entendem que a verdade é histórica. Por isso, continuar essa tradição significa, acima de tudo, não repetir os seus antecessores. $\mathrm{O}$ teórico crítico deve acompanhar o movimento histórico da sociedade e procurar superar seus antecessores, não com a pretensão arrogante de suplantar os seus mestres, mas com o objetivo de dar continuidade a essa tradição e acompanhar o movimento histórico. Nesses termos,

[...] faz teoria crítica todo aquele que pretende continuar a obra de Karl Marx (1818-1883). Isso não significa de maneira alguma que "continuar" seja simplesmente repetir o que Marx havia dito. Pelo contrário, Horkheimer insiste em que só é possível continuar a vertente intelectual da Teoria Crítica indicando primeiramente todos os pontos em que as análises inaugurais de Marx já não são suficientes para entender o momento presente. Dito de outra maneira, a ideia mesma da Teoria Crítica exige uma permanente atenção às transformações sociais, econômicas e políticas em curso e uma constante revisão e renovação das análises em vista de uma compreensão acurada do momento presente (NOBRE, 2008, p. 35).

A teoria crítica, portanto, caracteriza-se principalmente por ter no seu horizonte o compromisso com a emancipação e com a atenção permanente às transformações sociais. Nesse primeiro item, procurei sintetizar alguns aspectos fundamentais dessa tradição. Contudo, no próximo item, explorarei quais contribuições essa tradição pode oferecer à pesquisa educacional. Não tenho intenção de defender que a pesquisa normativa é mais importante do que a pesquisa empírica. Pelo contrário, como tentarei mostrar a seguir, ambas podem contribuir mutuamente para o objetivo de pensar os desafios educacionais contemporâneos.

\section{2}

Falar de uma unidade na teoria crítica é muito difícil. No entanto, desde Max Horkheimer, é possível encontrar algumas características que contribuem para a reflexão sobre os desafios da educação e suas instituições. Gostaria de me concentrar em dois elementos: a aproximação com as pesquisas empíricas e com as manifestações culturais e estéticas, ou seja, tentarei mostrar como a pesquisa educacional pode se beneficiar desse diálogo entre filosofia, pesquisa empírica e artes.

Max Horkheimer (1972) destacava a importância do diálogo entre a pesquisa normativa e a pesquisa empírica. Para esse pensador, ignorar os resultados das pesquisas empíricas é o mesmo que ignorar as transformações sociais, políticas e econômicas enfrentadas pela sociedade. De acordo com ele, essas pesquisas podem nos ajudar a identificar as patologias de uma sociedade e os potenciais emancipatórios não desenvolvidos por ela. 
Aliás, essa dicotomia entre pesquisa teórica e pesquisa empírica é responsável por muitos embates e debates nos programas de pós-graduação em educação. Infelizmente, é fácil encontrar grupos isolados e cada qual defendendo o seu tipo de pesquisa. Essa disputa apenas dificulta a identificação dos desafios da educação e suas instituições. Empenhados na defesa dos seus resultados, muitos pesquisadores deixam escapar a oportunidade de estabelecer um diálogo aberto, crítico e colaborativo com outras áreas.

Se pensarmos na história da filosofia, é inaceitável ignorar a sua matriz multidisciplinar. Desde o seu surgimento, a filosofia dialogava com as diferentes áreas de conhecimento. Filósofos, como Aristóteles, por exemplo, escreviam seus trabalhos depois de realizar pesquisas empíricas. No entanto, com o passar dos séculos e com a fragmentação das áreas de conhecimento, a filosofia precisou encontrar o seu lugar e a sua especificidade. Ao fazer isso, ela se distanciou das pesquisas empíricas, criando um abismo intransponível para muitos pensadores.

Para alguns filósofos, esse distanciamento era necessário para responder à sociedade e à academia a pergunta sobre a utilidade da filosofia. Concentrados em dar uma resposta sobre o lugar da filosofia, muitos não perceberam que forneciam armas para os seus oponentes. Daí o surgimento de filósofos que se concentraram tanto em responder sobre a utilidade da filosofia, que ignoraram a realidade que os circundava.

A teoria crítica e, de modo especial, o Instituto de Pesquisa Social de Frankfurt surgem com o objetivo de reaproximar a pesquisa qualitativa ou normativa da pesquisa quantitativa ou empírica. Seguidores de Marx, esses pensadores entendiam que era necessário olhar a realidade e nela encontrar os bloqueios à emancipação humana bem como as possibilidades de superação desses bloqueios. Ou seja, não adiantava buscar fora da realidade, fora do mundo material, as possibilidades para uma sociedade emancipada.

Os teóricos críticos estavam preocupados em criar um ambiente de pesquisa em que filósofos e sociólogos estivessem comprometidos com a sociedade. Fazer um diagnóstico de época tornou-se uma imposição a todo aquele que se filia a essa tradição. Diagnóstico que pode ser feito por um determinado pensador ou pela leitura de trabalhos empíricos feitos por outros. O mais importante é entender que não se pode fazer teoria crítica sem passar pela materialidade do mundo. Uma pesquisa de caráter normativo, filiada à essa tradição, não pode ignorar os dados empíricos fornecidos pela academia ou mesmo por órgãos públicos de pesquisa.

De outro modo, aqueles que fazem pesquisas empíricas não podem também ignorar a contribuição da filosofia para a elaboração de suas pesquisas e para a interpretação das informações coletadas. Apenas analisar essas informações sem 
considerar os objetivos sociais e os critérios que orientam as ações humanas pode conduzir a interpretações reducionistas da realidade social. Um diálogo franco, aberto e cooperativo é necessário não apenas para as pesquisas normativas, mas também para as pesquisas empíricas. Manter uma relação colaborativa fortalece todas as áreas envolvidas e cria um ambiente de cooperação multidisciplinar que ajuda significativamente a entender e, talvez, encontrar soluções para os problemas e as dificuldades educacionais mais urgentes.

A grande contribuição da teoria crítica para a pesquisa educacional é exatamente essa aproximação entre normativo e empírico. Alguns representantes dessa tradição, como Jürgen Habermas e Axel Honneth, falam de déficit sociológico ${ }^{1}$ e elaboram suas teorias com o objetivo de solucionar esse déficit. No entanto, embora alguns pensadores dessa tradição tenham se distanciado da relação colaborativa com as pesquisas empíricas, outros sempre estiveram preocupados em dialogar e acompanhar as informações coletadas por outras áreas do conhecimento.

Reaproximar talvez seja a melhor expressão a ser usada. Afinal, esse distanciamento entre teoria e prática só nos trouxe dificuldades. No âmbito das pesquisas educacionais, encontramos acervos de pesquisas completamente isoladas do mundo ou pesquisas que ignoram a normatividade e se concentram apenas nos dados coletados. De um lado, pesquisadores que não fazem mais do que reproduzir teorias e, de outro, aqueles que apresentam conclusões reducionistas e superficiais sobre a realidade educacional.

Um exemplo dessa aproximação entre a pesquisa normativa e a empírica é o trabalho de Andreas Gruschka. No seu livro recentemente publicado no Brasil, com o título Frieza burguesa e educação (2014), o autor procura explorar a contradição entre o discurso e a ação que Adorno e Horkheimer (1985) chamaram de frieza burguesa. Para esses pensadores, a frieza faz com que as pessoas aceitem as coisas como são e não tenham forças para transformar a sua realidade. No caso da educação e suas respectivas instituições, educandos e educadores aceitam o autoritarismo pedagógico com a promessa de uma emancipação futura. Ou seja, desde que, no futuro, as novas gerações alcancem a emancipação e estejam preparadas para a deliberação pública, no presente, são aceitáveis práticas autoritárias e repressivas. O próprio educando se convence, por exemplo, de que o castigo ou a punição no presente, embora dolorosos, são necessários para um futuro promissor. Na verdade, o educando na sua relação com o educador e esse na sua relação com a direção e outras autoridades veem-se enredados em uma situação profundamente complexa e paradoxal, na qual a realidade contraria a promessa. Afirma Gruschka: 
Assim, os alunos experimentam duas postulações diferentes conflitantes. Por um lado, trata-se de uma promessa humana e, por outro lado, da carapaça férrea da servidão (Weber) para obter maturidade em uma e adaptação na outra; para uma educação comum a todos aqui, e para seleção lá; para justiça como aceitação da especificidade do indivíduo aqui e a justiça como igualdade de tratamento de todos com o propósito de concorrência justa lá; para solidariedade incondicional aqui e para a individuação lá [...] Cada aula inicia com o empenho de todos em aprender tudo, e também o professor deve poder prometer ser capaz de transmitir toda a matéria. Mas depois se avança naturalmente com a matéria, mesmo quando muitos ainda não sabem aquilo que deveriam saber. $\mathrm{E}$ também a aula continua configurada de modo que, em vez de produzir uma aproximação do nível de conhecimento, continua acumulando conteúdos e assuntos não entendidos (2014, p. X-XI).

O livro de Gruschka é o resultado de um trabalho que, para identificar a frieza burguesa na educação, contou com pesquisas de campo que foram posteriormente discutidas e analisadas à luz da tradição normativa da teoria crítica. Depois da publicação do livro, foram realizadas ainda diversas pesquisas empíricas referentes à ontogenia da frieza burguesa. Não vou discutir os resultados dessa pesquisa, pois não é o objetivo deste artigo. Trago-o como exemplo de um importante trabalho que recupera as raízes dessa tradição e, ao mesmo tempo, contribui para pesquisa educacional.

A teoria crítica também pode estimular dois aspectos positivos presentes nas pesquisas normativas: sua pretensão crítica e reflexiva, o respeito e a referência à história da educação e a seus pensadores. Assim, por um lado, é necessário coletar dados e informações para um diagnóstico. Uma pesquisa na área de educação deve considerar o que já se produziu sobre educação, seja material ou teoricamente. Por outro, o pesquisador precisa olhar com agudeza crítica e reflexiva para a história e para os dados coletados a fim de verificar se eles contribuem ou bloqueiam a realização dos fins educacionais.

Exatamente nesse ponto, a teoria crítica aproxima-se muito do que denominamos de pesquisa normativa. Afinal, esse tipo de pesquisa está preocupado com os fins educacionais. Dito de outra forma, ela se interessa em investigar a finalidade da educação e quais são osbstáculos que impedem a concretização desse fim. Claro que o filiado à tradição da teoria crítica já assume de antemão que a finalidade da educação é contribuir para a formação de sujeitos emancipados, autônomos. Nisso pode residir uma crítica a essa tradição. Alguns podem perguntar se essa é mesmo a finalidade da educação ou se, por exemplo, seu fim seria somente preparar os indivíduos para o mercado de trabalho. Um pesquisador em educação filiado à teoria crítica não consideraria isso excludente. Contudo, ele faria uma forte crítica à educação voltada exclusivamente para o trabalho.

Os críticos da pesquisa normativa costumam defender que as investigações a respeito da educação deveriam estar isentas de valoração ou normatividade. Isto é, não poderíamos pensar como a educação deveria ser, mas, sim, o que ela é ou como 
ela é. Nesse sentido, a pesquisa educacional deveria orientar-se pela neutralidade. Contudo, ignoram esses críticos que a educação é uma criação e uma atividade humana, não estando livre de valoração. Quem educa deixa-se orientar por determinados valores e busca a concretização de um fim. $\mathrm{O}$ agir pedagógico não é possível sem uma orientação normativa.

E nesse aspecto, novamente, a teoria crítica pode contribuir, pois não basta reconhecer que o agir pedagógico orienta-se por determinados valores e por uma determinada finalidade. O pesquisador associado a essa tradição sabe que deve sempre questionar esses valores, essa orientação. Afinal, ele não pode ignorar as transformações que a sociedade enfrenta e os desafios que são postos à educação. Dessa forma, manter ativo o radar crítico e reflexivo permite evitar toda forma de relativismo, reducionismo ou dogmatismo.

Uma pesquisa em educação associada à tradição da teoria crítica, em primeiro lugar, significa trabalhar com a emancipação humana como finalidade. O pesquisador deve reconhecer que não existe uma educação amoral. Isso quer dizer que ele deve admitir sua orientação por aqueles valores que contribuem para a emancipação. Sua tarefa, portanto, é olhar para a realidade educacional e tentar identificar o que bloqueia e o que estimula a emancipação.

Nesse ponto, acredito que o filósofo da educação pode assumir uma postura mais humilde. Ele deve reconhecer seus limites e entender que sua tarefa não é transformar a educação desde uma posição normativa. Infelizmente, é muito comum encontrarmos tentativas de fazer da educação a redentora de todos os males sociais. Isso extrapola a tarefa das instituições educativas. Dizer que elas podem contribuir para a emancipação humana e, por consequência, para a sobrevivência e consolidação da democracia não significa que elas podem salvar a humanidade de todas as suas adversidades.

Desde o princípio, a tradição da teoria crítica manteve um relacionamento estreito com as manifestações culturais e estéticas. Os pensadores filiados a essa tradição usavam essas manifestações para interpretar os bloqueios e os potenciais emancipatórios. Adorno, Horkheimer, Kracauer, Benjamin, Habermas e Honneth estão entre eles. Comprometidos com a elaboração de um diagnóstico de época, esses pensadores buscavam uma possibilidade de interpretar o mundo material. Axel Honneth (2014), atual diretor do Instituto para Pesquisa Social de Frankfurt, afirma que talvez a melhor forma de entender uma época não seja mediante pesquisas sociais, mas pela literatura, cinema e as artes em geral. Podemos conhecer melhor as patologias sociais por meio das manifestações culturais e estéticas. 
En este sentido, el mejor camino para diagnosticar tales patologías sigue siendo, como en la época de Hegel o del joven Lukács, el análisis de los testimonios estéticos en los que tales síntomas se presentan indirectamente: las novelas, las películas o las obras de arte contienen aún el material a partir del cual obtenemos de manera primaria conocimiento acerca de si en nuestra época se pueden detectar tendencias de una deformación reflexiva, de un nivel superior, del comportamiento social y cuán difundidas están (HONNETH, 2014, p. 120).

Essas manifestações apresentam uma qualidade que nem sempre podemos encontrar nas pesquisas empíricas: um testemunho sobre a realidade. Por mais cuidadoso que seja um pesquisador, sua interpretação e sua forma de conduzir uma pesquisa empírica podem sofrer com fatores sobre os quais ele não tem controle. Por exemplo, ele pode encontrar um grupo de pessoas que não está disposto a ser sincero nas respostas de um questionário ou, ainda, pode encontrar pessoas, por razões que não precisamos discutir aqui, incapazes de manifestar em uma pesquisa empírica o que realmente pensam sobre o tema discutido.

No caso das manifestações culturais e estéticas, sem julgar sua qualidade, podemos encontrar traços característicos de uma época. No caso da educação, por exemplo, é muito comum constatar certo desprezo pelas instituições educativas. São raras as obras de arte que falam positivamente dessas instituições. Mesmo naquelas manifestações em que a educação é vista de forma positiva, isso só acontece porque $u m$ professor consegue transformar a realidade da instituição sozinho.

Como se vê, a título de exemplo, podemos perceber certo desprezo pelas instituições educativas. Algumas vezes, esse desprezo aparece em obras de arte com finalidade comercial. Mas também é possível encontrar trabalhos magníficos que abordam as instituições educativas como um ambiente opressor, antidemocrático e marcado pelo tédio. É o caso do professor e escritor francês Daniel Pennac, que, em Mal de escuela, de 2007, para além dos estigmas e dos rótulos, nos faz refletir sobre a educação e as instituições educativas desde a perspectiva de quem era considerado um mau aluno. Pennac revela o que muitos desses "alunos problemáticos" pensam:

Sí, es lo que hacen los zoquetes, se cuentan sin parar la historia de su zoquetería: soy nulo, nunca lo conseguiré, ni siquiera vale la pena intentarlo, está jodido de antemano, ya os lo había dicho, la escuela no es para mí... La escuela les parece un club muy cerrado cuya entrada se prohíben. Con la ayuda algunos profesores, a veces (2013, p. 21).

A experiência de Pennac é a mesma de muitos meninos e meninas. Eu mesmo tive experiências parecidas com as do novelista francês. Quando frequentava a educação básica, voltava para casa tomado de vergonha quando não conseguia acompanhar o professor e os meus colegas em uma determinada tarefa. Talvez, por isso, muitas crianças buscam outras estratégias para enfrentar essa vergonha: o 
mau comportamento, as brigas com professores e colegas e todo tipo de conduta que é, talvez, um grito de socorro.

Não tenho o objetivo de analisar manifestações culturais e estéticas neste artigo. Trata-se apenas de um exemplo da possibilidade de usá-las para pensarmos a realidade educacional, pois as obras de arte podem nos ajudar a compreender as dificuldades e as potencialidades adormecidas no ambiente educacional. Horkheimer argumentou que o Instituto de Pesquisa Social deveria adotar uma perspectiva multidisciplinar. Com essa postura, pretendia estabelecer princípios normativos com os quais poderia pensar as transformações sociais atualizando a pretensão crítica de Marx. Assim, seguindo as orientações de Horkheimer, o Instituto de Pesquisa Social propôs-se a realizar investigações sociais considerando as manifestações culturais e artísticas do seu tempo. De modo especial, a tradição da teoria crítica tratou de denunciar aquelas situações inaceitáveis na realidade social.

Essa é, sem dúvida, uma das características marcantes da teoria crítica. Para os pensadores dessa tradição, a arte está sempre ligada ao sofrimento. E a melhor forma de identificar os casos de sofrimento, muitas vezes reprimidos, é interpretar com atenção as manifestações culturais e artísticas. Podemos constatar situações inaceitáveis ou, nos termos de Honneth, patológicas. De modo especial, como supõe o autor alemão, ainda que a luta por reconhecimento de um indivíduo não seja verbalizada, sua pretensão será entendida pelos outros. O desprezo social se associa com formas de invisibilização ou coisificação do outro, o que seria, em última instância, uma tentativa de silenciar o outro. Nas criações artísticas, podemos ouvir essas vozes muitas vezes emudecidas ecoando através de outros mecanismos semióticos.

Pensar a educação seguindo de perto essa tradição significa olhar para a realidade educacional e identificar nela as situações patológicas. Nesse sentido, desvelar aqueles casos que, na verdade, contribuem para afastar o sujeito da possibilidade de alcançar sua emancipação. Como se trata de uma teoria que não é apenas descritiva, mas também normativa, o pesquisador tem a obrigação de identificar possibilidades emancipatórias adormecidas ou bloqueadas presentes nas instituições educativas.

Embora esse caráter normativo possa, em um primeiro momento, parecer uma atitude pretenciosa, na verdade, é uma obrigação do pesquisador em teoria crítica. Afinal, é um compromisso dessa tradição contribuir politicamente. Estar engajado política e socialmente é uma exigência que essa tradição procura manter viva. Parafraseando Adorno (2006), quando fala sobre educação, devemos nos preocupar em criar condições para que Auschwitz não se repita. 
Nesse sentido, as manifestações culturais e artísticas podem oferecer a oportunidade de identificarmos essas patologias e essas possibilidades emancipatórias no campo educacional. Isso não significa que podemos prescindir das pesquisas empíricas. Mas como faz parte dessa tradição aproximar-se dessas manifestações para interpretar uma determinada época, acredito que o papel do pesquisador pode até mesmo ser facilitado. Afinal, elas estão disponíveis a todos. Além disso, é inegável que são trabalhos que já estão prontos. Quer dizer, uma pesquisa empírica séria não pode ser feita rapidamente. Ela requer tempo para, inclusive, verificar se os dados coletados não foram corrompidos.

No caso das manifestações estéticas, estamos diante do testemunho individual e às vezes coletivo sobre um determinado tema. Contudo, o pesquisador deve ter 0 cuidado para não examinar apenas as manifestações que sirvam às suas hipóteses. Embora reconheçamos que nenhuma pesquisa é neutra, o pesquisador deve ter o cuidado de ser fiel à realidade, e não às suas pretensões políticas e normativas. Embora a teoria crítica preocupe-se com a emancipação humana, o pesquisador deve ter cautela para não se converter em um ditador da emancipação. Piores do que pesquisas superficiais são aquelas que pretendem servir de manifesto para salvação da humanidade.

Enfim, no decorrer deste artigo, procurei destacar a possibilidade de uma aproximação entre pesquisa normativa e pesquisa empírica. Associado à tradição da teoria crítica, entendo que podemos contribuir para pensar as patologias educacionais e, ao mesmo tempo, identificar os potenciais emancipatórios que podem ser estimulados. A educação e suas instituições precisam de pesquisadores engajados e capazes de cooperar. As anteriormente citadas disputas de território resultam em pesquisas, muitas vezes, superficiais ou tão especializadas que não contribuem para a educação pensar os desafios que se apresentam.

Nesse sentido, a filosofia da educação funda sua história como campo de conhecimento e ajuda a pensar a educação e os seus desafios no contexto complexo e plural das nossas sociedades. Característica principal de uma filosofia da educação que segue a tradição da teoria crítica é a aproximação da pesquisa empírica com a pesquisa normativa. Cabe ao pesquisador comprometer-se com a realidade educacional concreta. É preciso conhecer a realidade educacional, ou por meio de pesquisas de campo ou pelo acompanhamento das manifestações culturais e estéticas. Seguindo os fundadores Adorno e Horkheimer, fazer teoria crítica é assumir uma postura multidisciplinar e, além disso, comprometer-se para a sociedade não repetir as barbáries do passado e do presente. 


\section{Philosophy of education: contributions of critical theory for educational research}

\section{Abstract}

The present article has the objective to present some contributions of the Critical Theory for the education research. In this sense, firstly, I join this tradition that is guided by the ideal of emancipation. Secondly, recovering the origins of this tradition, I try to approach the normative research of empirical research and, in particular, cultural and aesthetic manifestations. I defend what an approximation between these researches help to identify the main challenges of education and its institutions in the complex and plural context of our societies. Finally, I emphasize the importance of educational research to assume a descriptive and normative approach. I mean, it is also necessary to identify the potential emancipatory not boosted in educational institutions.

Keywords: Critical theory. Education. Philosophy. Search.

\section{Nota}

1 O déficit sociológico da teoria crítica é o esquecimento do social. As teses sobre a dominação capitalista e a impossibilidade de superação dessa dominação produziram um diagnóstico de fechamento das potencialidades emancipatórias. Dessa forma, presos a noções universais de dominação, tornou-se impossível acessar o domínio do social.

\section{Referências}

ADORNO, Theodor. Educação e emancipação. São Paulo: Paz e Terra, 2006.

ADORNO, Theodor; HORKHEIMER, Max. Dialética do esclarecimento. Rio de Janeiro: Zahar, 1985.

DURKHEIM, Emile. Educação e Sociologia. In: FILLOUX, Jean-Claude. Émile Durkheim. Tradução de Celso do Prado Ferraz de Carvalho e Miguel Henrique Russo. Recife: Fundação Joaquim Nabuco; Massangana, 2010. (Coleção Educadores). p. 39-87.

GRUSCHKA, Andreas. Frieza burguesa e educação: a frieza como mal-estar moral da cultura burguesa na educação. Campinas: Autores Associados, 2014.

HONNETH, Axel. El derecho de la libertad: esbozo de una eticidad democrática. Madrid: Katz, 2014.

$34,2003$.

Luta por reconhecimento: a gramática moral dos conflitos sociais. São Paulo: Editora

HORKHEIMER, Max. Critical theory: selected essays. Nova York: Continuum, 1972.

NOBRE, Marcos. Curso livre de teoria crítica. Campinas: Papirus, 2008.

PENNAC, Daniel. Mal de escuela. Barcelona: Contemporánea Debolsillo, 2013.

ROUSSEAU, Jean-Jacques. Emílio ou da Educação. São Paulo: Martins Fontes, 2004. 